\title{
Nanophotonics
}

Nanophotonics.SPIEDigitalLibrary.org

\section{Publisher's Note: Special Section on Nanocarbon Photonics and Optoelectronics}

\section{SPIE.}




\section{Publisher's Note: Special Section on Nanocarbon Photonics and Optoelectronics}

Three articles in the Special Section on Nanocarbon Photonics and Optoelectronics were originally published with erroneous citation identifiers (CIDs).

"Study of collective radial breathinglike modes in double-walled carbon nanotubes: combination of continuous two-dimensional membrane theory and Raman spectroscopy" by Dmitry I. Levshov et al. was published 22 September 2015 with a CID of 103599 and was republished with a CID of 012502 on 9 October 2015.

"Fluid modeling for plasma-enhanced direct current chemical vapor deposition" by Rinat R. Ismagilov et al. was published 28 September 2015 with a CID of 103598 and was republished with a CID of 012503 on 9 October 2015.

"Carbon nanotube photonics: using microring resonators for tailoring semiconducting carbon nanotubes photoluminescence" by Adrien Noury et al. was published 8 October 2015 with a CID of 102599 and was republished with a CID of 012513 on 16 October 2015.

This change affects the official citation for these three papers, and was made in order for the first two numbers of the CID to reflect the issue of publication, 01 .

(C) 2015 Society of Photo-Optical Instrumentation Engineers (SPIE) 